\title{
Learning through technology in middle school classrooms: Students' perceptions of their self-directed and collaborative learning with and without technology
}

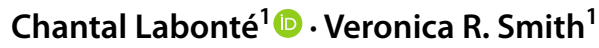

Received: 10 June 2021 / Accepted: 16 December 2021 / Published online: 6 January 2022

(C) The Author(s), under exclusive licence to Springer Science+Business Media, LLC, part of Springer Nature 2022

\begin{abstract}
In the present study, students' perceptions of their self-directed and collaborative learning with and without technology were examined in ICT-supported middle school classrooms. Three hundred and twenty middle school students from eight schools across Alberta, Canada participated in the study by completing a questionnaire. Descriptive statistics, independent sample t-test, one-way ANOVA and correlational analysis were used to analyse the questionnaire responses. Descriptive statistics revealed that middle school students perceive themselves as readily engaging in self-directed and collaborative learning within their classrooms. Students' self-directed learning with and without technology was significantly related to the instructional quality in their classroom with lower instructional quality classrooms having a significant small effect on self-directed learning. Gender was also found to have a small effect, with girls more readily engaging in self-directed learning, although this difference was not sustained when using technology. When learning with technology, while indicating that they engage in self-directed learning within their classrooms, students reported less engagement in collaborative activities with their peers, particularly in earlier middle school grades. Students may benefit from additional support to engage in collaborative activities while using technology. Likewise, teachers may benefit from professional development to support their facilitation of self-directed learning and collaborative learning as well as implementation of technology within the classroom.
\end{abstract}

Keywords Collaborative learning $\cdot$ ICT-supported learning $\cdot$ Self-directed learning

Chantal Labonté

clabonte@ualberta.ca

Veronica R. Smith

vs2@ualberta.ca

1 Department of Educational Psychology, Faculty of Education, The University of Alberta, Edmonton, Alberta T6G 2G5, Canada 


\section{Introduction}

Increased access to information communication technologies (ICT) in classrooms across the world over the last two decades has transformed pedagogical practices (Collins \& Halverson, 2010). Most recently, the COVID-19 pandemic has necessitated the use of ICT, transforming student learning further, as students began home-based online learning at an unprecedented rate (Wen et al., 2021). As students return to in-person learning, emphasis remains on preparing students to enter our complex technology and media-driven environment where devices and applications change rapidly, information is readily accessible, and there are increasing opportunities for large-scale collaborations. Collaborative learning (CL) and self-directed learning (SDL) have been recognized as necessary competencies to prepare students for the current global knowledge society (Henry, 2015; Partnership for 21st Century Skills, 2011; Voogt \& Roblin, 2012).

ICT has been recognized for its potential in supporting the development of SDL (Morris \& Rohs, 2021) and CL (Akhigbe, 2021; Resta \& Laferriere, 2007). With emphasis placed on fully utilizing ICT in the classroom, there is a need to understand how the development of SDL and CL can be promoted in ICTsupported learning environments, particularly within K-12 classrooms where research has been lacking (Morris \& Rohs, 2021). Teachers' positive perceptions and attitudes towards ICT have been identified as a significant factor in the successful integration of ICT in the classroom (Arkoful et al., 2021; Bas \& Bastug, 2021; Khlaif, 2017; Semerci \& Aydin, 2018; Xie et al., 2021). Students themselves also play a role in the success of ICT-supported learning and skill acquisition. Students' perceptions of their learning affect motivation and the ability to succeed academically (Bandura, 1993; Schwartz et al., 2016). Therefore, there is a need to understand students' perceived ability to engage in SDL and CL both with and without technology in order to better understand how to support students' ability to take full advantage of their learning opportunities. The present study examines middle school students' perceptions of their SDL and CL with and without technology.

\subsection{Self-directed and collaborative learning}

SDL has become an essential learning process for achieving meaningful educational outcomes. SDL occurs when knowledge, skills, or personal development are attained by an individual through his or her own efforts (Gibbons, 2002). During SDL, learners take initiative and responsibility for the planning, completion and review of their learning process and outcomes (Bolhuis, 2003; Garrison, 1997; Morris \& Rohs, 2021). By doing so, they are able to customize their approach to learning tasks (Gibbons, 2002). Readiness towards SDL has been associated with a variety of meaningful learning skills and outcomes, including critical and logical thinking skills (Willett et al., 1983), academic achievement (Stewart, 2007), and an increase in students' engagment and understanding of course content (Findlater et al., 2012). 
SDL is often viewed as implying a purely individual pursuit of knowledge and learning goals (Bolhuis, 2003). However, students who are engaged in SDL may receive a variety of support from teachers and peers to complete their learning goals (Robertson, 2011). The quality of these interactions with teachers and peers has an influence on the student's motivation to persist with their SDL goals (Szeyeng \& Hussain, 2010). Self-directed learners work closely with other students and adults (Gibbons, 2002). As such, SDL goes hand in hand with CL. CL refers to two or more students working towards a goal (Dillenbourg, 1999). When students are engaged in CL, they develop and work towards a shared learning goal (Clark, 2001; Dillenbourg, 1999), and take on the perspective that others are a source of expertise and knowledge (Henry, 2015). In the classroom, CL occurs during tasks that encourage students to assist each other in such a way that the less competent members will benefit from the assistance that they receive from the more skillful peers whose learning is advantaged in return by their role as teacher (Bjorklund, 2012). CL has been associated with greater conceptual understanding (O'Donnell, 2006), greater academic achievement (Hussain et al., 2011; Springer et al., 1999), great content knowledge and skills (Hussain et al., 2011; Terenzini et al., 2001), and greater critical thinking skills (Gokhale, 1995).

\subsection{ICT-supported self-directed learning and collaborative learning}

Within an ICT-supported learning environment, students learn in an environment that blends face-to-face and technology-based activities. ICT provides instructional affordances to facilitate both SDL (Morris \& Rohs, 2021) and CL (Akhigbe, 2021; Resta \& Laferriere, 2007). Students in K-12 classrooms perceived the use of technology in their classroom to be important for their learning (Quaddumi et al., 2021). While ICT can support the acquisition and use of these skills, technology itself cannot have an impact on students who have not developed collaborative and selfdirected learning processes (Lee et al., 2014).

When adult learners used web platforms, such as Moodle, Google Classroom, and Wikispaces, researchers have found that the use of technology empowers students' ability to engage in SDL, although participants experienced an initial learning curve (Sze-yeng \& Hussain, 2010). Within the higher education setting, students with higher perceptions of their ICT-supported learning tended to be more engaged and demonstrated greater outcomes (Cole et al., 2021). In university students, SDL skills were associated with ICT-supported learning, while gender and age were not related to ICT use (Lee et al., 2017). Among high school students, students' ICTsupported SDL did not differ across gender (Eroglu \& Ozbek, 2018; Gokcearslan, 2017). Among a sample of Grade 8 students, Dwiyanti et al. (2020) found that, while students were generally ready to engage in online learning, students continued to require support to develop their SDL skills and online communication selfefficacy (Dwiyanti et al., 2020). Within K-12 learning, Bartholomew et al. (2017) found that access to mobile devices was significantly related to higher student performance, although it was not significantly related to SDL processes. Students often 
require support and guidance on how to use ICT in order to effectively engage in SDL (Morris \& Rohs, 2021).

When technology is introduced within CL, the CL processes have been found to be similar to when learning without technology (Garris et al., 2018). ICT tools can be used to mediate access to shared content and the quick and efficient exchange of ideas (Shamir-Inbal \& Blau, 2021). When engaging in CL in online environments, some students may feel less intimidated to participate in group discussions than in a face-to-face context, affording those students equal access to participation (O'Donnell, 2006). Among higher education students, students' use of social media and interactions with their peers and teachers influence students' engagement in CL and their learning performance (Qureshi et al., 2021). Male higher education students have demonstrated greater readiness and aptitude towards technology-supported CL (Khalifeh et al., 2020). When higher-education students engaged in CL within online networks, students experience higher academic achievement, greater mastery of subject matter, and increased success during problem-solving tasks, compared to students who engage in computer-mediated learning independently (Resta \& Laferriere, 2007). Higher education students also perceived ICT-supported CL to enhance their learning outcomes (Tanrikulu, 2020).

\subsection{Present study}

With the increased access to ICTs and a push towards developing SDL and CL competencies within classrooms, there is a need to understand students' perceived ability to engage in SDL and CL both with and without technology in order to better understand how to support students' ability to take full advantage of their learning. Given the relationship between students' SDL and CL in non-technological settings and their ability to engage in SDL and CL with technology (Lee et al., 2014), the assessment of students' perceptions of their learning skills is of a particular interest as students' perceptions and beliefs about their learning have an effect on their ability to succeed academically (Bandura, 1993; Schwartz et al., 2016). By examining the extent that students apply SDL and CL across settings, the development of pedagogical practices that foster and facilitate SDL and CL in ICT-supported classrooms can be developed and bolstered. Despite the importance of SDL and CL, the development of these learning processes are not yet fully understood in the K-12 setting, with research lacking in many areas (Morris \& Rohs, 2021). The present study examines middle school students' perceptions of their SDL and CL with and without technology. The research is guided by the following question: To what extent do middle school students perceive themselves to be engaged in SDL and CL in their ICT-supported classrooms?

The study was conducted in Alberta, Canada where technology is readily available and accessible in $\mathrm{K}$ to 12 classrooms through provincial governmental policies. Alberta Education's Learning and Technology Policy Framework (Alberta Education, 2013) articulates the commitment to ICT-supported SDL and CL within the province, and calls for technology to be used as a means tor provide students with a variety of ways to "learn, communicate, collaborate, ask important questions, solve 
problems, and demonstrate what they know and can do", (Alberta Education, 2013; p. 21) allowing for students the choice of how they wish to engage in their learning. To facilitate the implementation of ICTs within classrooms, Alberta Education provided infrastructure (i.e., Internet connectivity, technological tools such as computers and tablets) for schools and resources for teachers (Pich \& Kim, 2004). Given the emerging use of technology in Alberta classrooms, we hypothesize that students will perceive themselves to readily engage in SDL and CL with and without technology in their classrooms.

\section{Method}

\subsection{Research design}

This study employed a survey design with descriptive analyses, correlational analyses and an analysis of variance used to explore the extent that middle school students perceive themselves to engage in SDL and CL with and without technology. A survey design allows for a quantitative description of trends within a population by studying a sample drawn from the population (Cresswell, 2014).

\subsection{Participants}

Three hundred and twenty-five students (52.6\% male) from 8 schools and 19 classrooms across 5 school jurisdictions were asked to participate by completing a questionnaire. Of these students, five students did not complete all the items in the questionnaire. Results of Little's (1988) missing completely at random (MCAR) test were non-significant (chi-square $=9.82, \mathrm{df}=26$, sig $=0.998$ ), suggesting that the missing items were missing at random. Given that only a few cases had missing values and they were found to be missing at random, all 5 participants with missing values were deleted from the data set (Tabachnick \& Fidell, 2014). A total of 320 students enrolled in grades 5 to 9 were retained. The total population of students in these grades in Alberta was 236,268 at the time of data collection according to available Alberta Education data. (Alberta Education, n.d.). Students were enrolled in grades 5 to 9 . The majority of students were in Grade 8 (55.3\% of the sample).

Table 1 Distribution of students in each grade per school

\begin{tabular}{|c|c|c|c|c|c|c|c|c|c|}
\hline \multirow[b]{2}{*}{ Grade } & \multicolumn{8}{|c|}{ School } & \multirow[b]{2}{*}{ Total } \\
\hline & A & B & $\mathrm{C}$ & D & $\mathrm{E}$ & $\mathrm{F}$ & G & $\mathrm{H}$ & \\
\hline 5 & 0 & 4 & 0 & 0 & 5 & 1 & 0 & 0 & 10 \\
\hline 6 & 0 & 8 & 0 & 0 & 1 & 0 & 0 & 0 & 9 \\
\hline 7 & 22 & 0 & 0 & 11 & 2 & 17 & 0 & 0 & 52 \\
\hline 8 & 39 & 10 & 50 & 7 & 3 & 0 & 68 & 0 & 177 \\
\hline 9 & 34 & 4 & 0 & 16 & 0 & 0 & 0 & 18 & 72 \\
\hline Total & 95 & 26 & 50 & 34 & 11 & 18 & 68 & 18 & 320 \\
\hline
\end{tabular}


Table 1 provides the distribution of students in each grade per school. All students were in inclusive ICT-supported classrooms where students with mild to moderate learning needs ranged from 10 to $85 \%$ per classroom. $64.4 \%(n=206)$ of the participants came from English speaking families.

Participating schools were part of a larger study. All school jurisdictions across Alberta were invited to participate in the study. Eight schools across five school jurisdictions participated based on expressed interest and availability of teaching staff. Participating schools were located in both rural and population centers across various regions of Alberta, Canada. A rural centre refers to areas outside of population centers, defined as areas with a population of at least 1000 and a population density of at least 400 people per square kilometre. Small population centres have a population between 1000 and 29,999, whereas medium population centres have a population between 30,000 and 99,999. Four schools were located in areas classified as small population centers and 2 schools were located in areas classified as medium population centers based on the 2011 Canadian census population estimates (Statistics Canada, 2011).

ICT was integrated into students' classrooms across subject areas. A variety of technological devices (e.g. laptops, tablets, smartphones) were used in participating classrooms to complete assigned tasks, access learning management systems, create reports and presentations, access information using the Internet, and use a variety of applications for multimedia creations. Student technology use varied by classroom but, on average, students actively used technology for educational purposes $71.22 \%$ of the time. Observations of teacher technology use revealed that the majority of the time $(66.63 \%)$ teachers used technology indirectly as a means to support their practice.

Teachers all provided a similar quality of instruction in their classroom. The quality of classroom instructional across students was measured using the Classroom Assessment Scoring System-Secondary (CLASS-S), an observational protocol used to examine the quality of classroom practice across the domains of emotional support, classroom organization and instructional support (Pianta et al., 2012). Using the CLASS-S, coders assign a score along a scale from one to seven where a score of 1 or 2 falls within the low range, a score of 3 to 5 falls within the mid-range, and a score of 6 to 7 falls within the high range. Teachers were observed across at least two complete classroom sessions. Across all 19 teachers, aggregated across observational periods, the average quality of instruction fell within the mid-range at 4.75, with a minimum score of 4.14 and a maximum score of $5.80(\mathrm{SD}=0.39)$. Across aggregated observations, teachers provided instruction that was of mid-range in quality based on the CLASS-S.

\subsection{Procedure}

Data were collected and managed using REDCap electronic data capture tools (Harris et al., 2009). The study questionnaire was administered, via REDCap, to students mid-school year. Students completed the questionnaire within their respective classrooms. A research assistant provided instructions via video embedded within the 
online platform to help students complete the questionnaire. The computer read each item aloud to the student.

\subsection{Measure}

Students' perceptions of their SDL and CL with and without technology within ICT-supported classroom environments was assessed using a 14-item questionnaire found to be reliable and valid with middle school students in Canada (Labonté \& Smith, 2019). The questionnaire is adapted from Lee et al. (2014) who initially developed the questionnaire in order to understand high school students' SDL and CL in ICT-supported classrooms in Singapore (Lee et al., 2014). The questionnaire was selected based on its evidence of validity for use with our sample (Labonté \& Smith, 2019) and its alignment with the purpose of the research (Lee et al., 2014). The questionnaire assesses students' perceptions of their learning across four scales:

1) self-directed learning without technology (SDL) scale; this scale is comprised of 3 items and measures students' perceptions of the extent of their ability to direct their learning in face-to-face non-technological settings and includes items such as 'In this class, I try to determine the best way to work on the assignments.',

2) collaborative learning without technology (CL) scale; this 4-item scale assesses students' perceptions of their participation in CL opportunities such as group discussions within face-to-face non-technological settings and includes items such as 'In this class, my classmates and I actively work together to help each other understand the material.',

3) self-directed learning with technology (SDLT) scale; which is made up of 4 items and measures student's perceptions of their role in directing their learning in ICT-supported learning environments including items like 'In this class, I use the computer to keep track of my learning progress.', and

4) collaborative learning with technology (CLT) scale; this 3-item scale assesses student's perceptions of their participation in CL opportunities such as group discussions in ICT-supported learning environments and includes items such as 'In this class, my classmates and I actively communicate via online platforms (e.g. Forum, MSN, wiki) to learn new things together.'.

Each item required a response on a 7-point Likert scale (i.e., 1- strongly disagree, 7 -strongly agree). The average ratings of items within a scale was used as the scale score.

\section{Results}

Examination of the mean and standard deviations, found in Table 2, reveals that, overall, students in our sample report their SDL, CL, and SDLT as slightly more agreeable (means over 5). The mean score for CLT is 4.27 on the 7-point Likert scale. The SDL scale had the highest mean scale, and the CLT scale is the lowest 


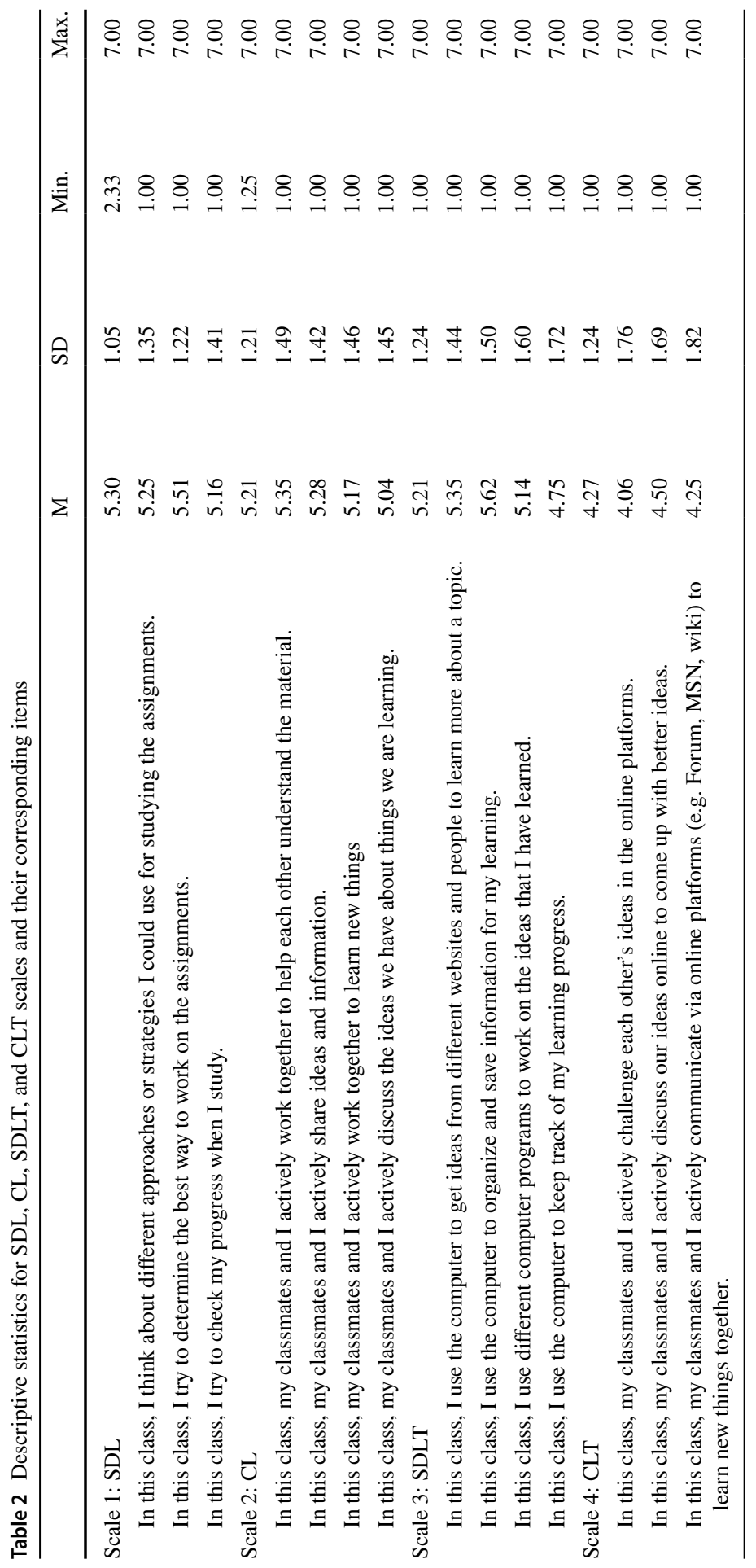


scale, on average. An examination of the range of students' responses revealed that for all questionnaire items students endorsed the full range of Likert response possibilities (i.e., strongly disagree to strongly agree).

Correlation analysis revealed a significant relationship $(p=0.04)$ between instructional quality and ratings of SDL. No other significant relationships between overall instructional quality and students' perceptions of their learning were found. When students' ratings were examined based on whether they were in a classroom with high or low levels of instructional quality (groups separated by the median score of 4.697), t-test analysis revealed a significant difference among the ratings of students on SDL $(p=0.008)$ and $\operatorname{SDLT}(p=0.001)$. Students who were in classrooms with lower ratings $(n=163)$ of instructional quality reported an average rating of $5.46(\mathrm{SD}=1.03)$ for SDL and an average rating of $5.44(\mathrm{SD}=1.01)$ on SDLT, whereas students who were in classrooms with higher ratings of instructional quality $(\mathrm{n}=157)$ reported an average rating of $5.15(\mathrm{SD}=1.03)$ on SDL and an average rating of $4.98(\mathrm{SD}=1.34)$ on SDLT. The effect of the quality of instructional was found to be small, with a Cohen's $d$ of $0.30 \mathrm{SD}$.

Students' perceptions of their learning were examined across gender and grade. Correlation analysis revealed a significant relationship between gender and SDL $(p=0.05)$. No significant relationships were found among the other scales and gender. A one-way analysis of variance revealed a significant gender difference $(p=0.05)$ on the SDL scale. Girls reported a mean score of $5.43(\mathrm{SD}=1.06)$ on the SDL scale, whereas males reported a mean score of $5.20(\mathrm{SD}=1.02)$. The effect of gender was found to be small, with a Cohen's $d$ of 0.22 SD. No significant difference was found among the other scales across genders. When the difference between gender was examined based on the students' respective grades, only a significant difference between boys $(\mathrm{M}=5.10, \mathrm{SD}=1.11)$ and girls $(\mathrm{M}=5.50, \mathrm{SD}=1.11)$ was found among grade 8 students. Grade 8 students make up the largest subset of the sample, with 177 grade 8 students included.

Correlation analyses did not find any significant relationships between grades and the four scales measured. However, a one-way analysis of variance revealed that students' CLT varied across grades $(\mathrm{F}(4,315)=2.93, p=0.02)$. Despite reaching a level of statistical significance, the actual difference in mean scores across grades for CLT was small (eta squared of 0.04). Post-hoc comparisons using the Tukey HSD test indicated that the perception of grade 5 students' CLT $(M=2.7, \mathrm{SD}=1.49)$ was significantly different from that of grade 7 students $(M=4.38, S D=1.18)$, grade 8 students $(M=4.30, S D=1.57)$, and from that of grade 9 students $(M=4.33$, $\mathrm{SD}=1.42$ ) at a 0.05 level.

\section{Discussion}

Twenty-first century learners need to be prepared for the global knowledge society. CL and SDL have been recognized as necessary competencies that students need to acquire (Henry, 2015; Partnership for 21st Century Skills, 2011; Voogt \& Roblin, 2012). Despite a focus on these skills, their development is not fully undestood within a K-12 setting (Morris \& Rohs, 2021). The aim of the present study was to 
explore middle school students' perceptions of their CL and SDL with and without technology. The assessment of students' learning skills both with and without technology is of particular interest to educators as students' who have not developed collaborative and self-directed ways of learning may not be able to take full advantage of the benefits of ICT-supported learning. Additionally, the assessment of students' perceptions of the extent of their ability to engage in SDL and CL is an important consideration as students' perceptions and beliefs about their learning have a direct effect on their ability to learn and succeed (Bandura, 1993; Schwartz et al., 2016).

Our results suggest that students readily engage in SDL and CL during non-technology supported learning. On average, no student in the sample strongly disagreed in their ability to engage in some degree of SDL and CL in their classrooms. Middle school students are indeed readily engaging with both SDL and CL. Students perceived engagement in SDL and CL in non-technology supported learning environments suggests that they are using and acquiring CL and SDL skills. Lee et al. (2014) found a positive relationship exists between SDL and CL use without technology and with technology among high school students in Singapore, in such a way that students' ability to engage in SDL and CL without technology predicted their ability to do with technology (Lee et al., 2014). The finding that students are engaging in SDL and CL without technology holds promise for their ability to do so when learning with technology, and suggests that students are acquiring necessary learning skills to allow them to take full advantage of learning in technology-supported environments.

When asked about their perceived engagement in SDL in technology-supported learning environments, students, on average, reported readily engaging in SDL, although the range of scale scores suggest that some students strongly disagree with the notion that they engage in SDL with technology to any extent. When asked about their perceived engagement in CL in technology-supported learning environments, students reported less engagement, on average, in collaborative activites with technology in their classrooms. The range of scale scores suggest that some students are readily engaging (i.e, agree and strongly agree) in such tasks while other students are not (i.e., ratings of disagree and strongly disagree). The results suggest that although students have the skills to engage in CL when not using technology, they may require additonal support and opportunitity to engage in CL with technology in their classrooms. Students may benefit from additional support to use technology in collaborative tasks. Tools such as email, online chat forums, blogs, wikis, videoconferencing systems, and course management systems have all been used to support online CL (Resta \& Laferriere, 2007). These Internet tools and technologies allow for an active rather than a passive process of receiving and evaluating information (Domalewska, 2014). Additionally, CL with technology does not only occur within online networks, it can also occur when peers engage in the use of ICT together collaboratively (Blaye et al., 1991). Teachers might benefit from additional professional development to support their ability to integrate technology for various uses in their classrooms.

Are students' perception of their learning influenced by the instructional quality in their classroom? Our results suggest that the instructional quality experienced in the classroom did not have a significant impact on students perceived ability to 
engage in CL and CLT. However, the quality of instruction in the classroom did influence students' perception of their engagement in SDL and SDLT. Students who were in classrooms with lower levels of instructional quality perceived themselves to be more engaged in SDL processes with and without technology compared to students who received a higher quality instructional support. It appears that in classrooms where teachers were observed to provide lower levels of direct instructional support that students were able to be more independent in their learning resulting in more students taking initiative and responsibility over their learning. Further research is required to better understand the relationship between SDL and teacher's instructional quality and pedagogical approaches in ICT-supported classrooms.

Students' perception of their engagement in SDL and CL with and without technology differ across both gender and grades. Overall, girls reported more perceived ability to engage in SDL compared to boys. However, the effect size of the differences in means across gender was small. When gender was covaried by graded, a statistically significant difference on SDL only remained for grade 8 students who make up the largest subset of the sample. An effect of gender has not been found within older samples of higher education students (Lee et al., 2017) or high school students (Eroglu \& Ozbek, 2018). From a maturation perspective, grade 8 girls undergo developmental changes associated with puberty that may allow them to more easily engaged in self-directed processes compared to boys of the same age. Neuropsychological research into the development of executive functioning skills has demonstrates that task performance dips at the onset of puberty but then improves again after puberty (Blakemore \& Choudhury, 2006). Executive functioning refers to a set of basic information-processing abilities used to regulate attention and goal-oriented behaviour. Children rely on executive functioning abilities to engage in complex social and cognitive activities (Bjorklund, 2012). When engaging in SDL, students must be able to prepare and plan their learning, to carry out learning independently, and to adjust their behaviour in order to reach their learning goal (Robertson, 2011). Executive functioning is one psychological function that allows students to carry out SDL (Simons, 2000). The onset of puberty decreases performance on tasks requiring executive functioning, which may result in less engagement in SDL. The onset of puberty occurs earlier for girls (10 to 11 years of age) compared to boys (11 to 12 years of age) (Blakemore \& Choudhury, 2006). Given that students are typically 12 to 13 years of age in grade 8 , girls, whose onset of puberty occurs earlier than boys, may be more able to engage in SDL. While this maturation view of executive functioning is well documented in neuropsychological literature, the pattern of difference in SDL engagement between girls and boys was not found for Grade 6 and 7 students which is when we would expect the onset of puberty to occur for girls. Further research is required to better understand the role of the development of executive function, and other cognitive skills, related to SDL.

\subsection{Limitations and future research}

The sample was a non-probabilistic convenience sample. Although convenience samples are commonly used in research, a non-random sample limits the 
generalization of the results (Elfil \& Negida, 2017). Further research among middle school students is required. Within our sample, a significant limitation is that students were not equally distributed across grades. Students in grade 5 made up only a small percentage $(3.1 \%)$ of the overall sample of students, whereas grade 8 students made up the largest percentage of the overall sample $(55.3 \%)$. The uneven distribution of students may have limited our ability to detect statistical differences across grades. Additional research is needed to examine difference in SDL and CL in ICTsupported classroom across the middle school grades.

Based on the individual items in the questionnaire, it is impossible to conclude whether the variance in students' perceived engagement in SDL and CL is due to individual differences in students' proficiency in engaging in SDL and CL, or if the difference in students' perceived ability to engage in SDL and CL is due to variation in pedagogical appproaches to using ICT in their respective classrooms. Across Alberta, a variety of technology implementation strategies have been adopted by schools. Jurisdiction technology implementation strategies may influence pedagogical practices surrounding the use of ICT for SDL and CL. Furthermore, pedagogical differences across grade level may also influence the opportunities for students to engage in SDL and CL. For example, grade 5 students report less perceived engagement in CL with technology than grade 7, 8, and 9 students. Pedagogical differences may allow grade 7, 8, and 9 students more opportunities to engage in CL with technology than grade 5 students. Additionally, differences in the approaches of integrating ICT for SDL and CL may differ across subject areas. Although students in our sample experienced the use of ICT across subject areas, some subject areas may more easily and effectively lend themselves to certain pedagogical approaches over others. Futher research is needed to better understand the factors that contribute to the variation in students' engagement with SDL and CL in their ICT-supported classrooms.

\subsection{Practical implications}

SDL and CL skills are recognized for their importance in preparing students for the current global knowledge society (Henry, 2015; Partnership for 21st Century Skills, 2011; Voogt \& Roblin, 2012). Students in our sample are engaging in SDL and CL within their classrooms, although teachers who offer less instructional support tended to have students who are more engaged in SDL compared to teachers with higher instructional quality. In order for SDL to occur, teachers must provides students with the opportunities to take initiative, planning and responsibility over their learning (Morris \& Rohs, 2021).

When learning with ICTs, middle school students require more support and opportunity to engage in ICT-supported learning, particularly in the area of CL. Teachers may benefit from additional professional development and support to facilitated ICT-supported CL, particularly in early grades as CLT was less common among Grade 5 students in our sample. Within our middle school sample, girls appear to be more developmentally prepared to engage in SDL compared to boys. However, this effect disappears when using technology. Students continue to require 
support to develop SDL and CL skills, even when readily engaged in ICT-supported learning. This is consisent with prior research in both $\mathrm{K}-12$ and higher education settings (Bartholomew et al., 2017; Dwiyanti et al., 2020; Lee et al., 2014; Morris \& Rohs, 2021).

\subsection{Conclusion}

The present study examined middle school students' perceptions of their CL and SDL with and without technology. To our knowledge, this is the first study to examine middle school students' perceptions of both SDL and CL with and without technology, contributing to a limit body of literature on students' perceptions of their ICT-supported learning. The results revealed that students are engaging in SDL and CL in their classrooms. Students indicated that they engage less in collaborative activities (i.e., sharing ideas, discussion, working with peers) with technology. Girls tend to more readily engage in SDL but this gender-based difference disappears when learning with technology.

Acknowledgements Parts of this paper were developed as a Masters of Education thesis by the first author. Funds received by Veronica R. Smith from Alberta Education "Flexible Pathways to Success: Technology to Design for Diversity" grant supported this study.

Code availability Not applicable.

Funding Funds from Alberta Education "Flexible Pathways to Success: Technology to Design for Diversity" grant supported this study.

Data availability A copy of the questionnaire used in the study can be accessed by emailing the first author.

\section{Declarations}

Conflict of interest The authors declare that they do not have any conflict of interest. The Research Ethics Board at the University of Alberta approved all study procedures.

\section{References}

Akhigbe, J. (2021). Leveraging collaborative mobile learning instructional pedagogy in the era of COVID-19. Academia Letters, 2320, 1-5. https://doi.org/10.20935/AL2320

Alberta Education. (2013). Learning and technology policy framework. School Technology Branch.

Alberta Education. (n.d.). Student population statistics. Retrieved November 7, 2021, from Government of Alberta: https://www.alberta.ca/student-population-statistics.aspx

Arkoful, V., Barfi, K., \& Aboagye, I. (2021). Integration of information and communication technology in teaching: Initial perspectives of senior high school teachers in Ghana. Education and Information Technologies, 1-18. https://doi.org/10.1007/s10639-020-10426-7

Balta, N., \& Awedh, M. (2017). The effect of student collaboration in solving physics problems using an online interactive response system. European. Journal of Educational Research, 6(3), 386-394. https://doi.org/10.12973/eu-jer.6.3.385

Bandura, A. (1993). Perceived self-efficacy in cognitive development and functioning. Educational Psychologist, 28(2), 117-148. https://doi.org/10.1207/s15326985ep2802_3 
Bartholomew, S., Reeve, E., Veon, R., Goodridge, W., Lee, V., \& Nadelson, L. (2017). Relationships between access to mobile devices, student self-directed learning, and achievement. Journal of Technology Education, 29(1), 1-24.

Bas, G., \& Bastug, M. (2021). Teaching-learning conceptions, teaching motivation, and perceptions towards ICT: A research in Turkish public high schools. Education and Information Technologies, 26, 1607-1625. https://doi.org/10.1007/s10639-020-10324-y

Bjorklund, D. (2012). Children's thinking: Cognitive development and individual differences (5th ed.). Wadsworth Cengage Learning.

Blakemore, S.-J., \& Choudhury, S. (2006). Development of the adolescent brain: Implications for executive function and social cognition. Journal of Child Psychology and Psychiatry, 47(3/4), 296-312.

Blaye, A., Light, P., Joiner, R., \& Sheldon, S. (1991). Collaboration as a facilitator of planning and problem solving on a computer-based task. British Journal of Developmental Psychology, 9, 471-483.

Bolhuis, S. (2003). Towards process-oriented teaching for self-directed lifelong learning: A multidimensional perspective. Learning and Instruction, 13, 327-347. https://doi.org/10.1016/S0959-4752(02) 00008-7

Clark, J. (2001). Stimulating collaboration and discussion in online learning environments. Internet and Higher Education, 4, 119-124.

Cole, A., Lennon, L., \& Weber, N. (2021). Student perceptions of online active learning practices and online learning climate predict online course engagement. Interactive Learning Environments, 29(5), 866-880. https://doi.org/10.1080/10494820.2019.1619593

Collins, A., \& Halverson, R. (2010). The second education revolution: Rethinking education in the age of technology. Journal of Computer Assisted Learning, 26, 18-27. https://doi.org/10.1111/j.13652729.2009.00339.x

Cresswell, J. (2014). Research desigh: Qualitative, quantitative, and mixed methods approaches (4th ed.). Sage Publications, Inc.

Dillenbourg, P. (1999). What do you mean by 'collaborative learning'? In P. Dillenbourg (Ed.), Collaborative-learning: Cognitive and computational approaches (pp. 1-19). Elsevier.

Domalewska, D. (2014). Technology-supported classroom for collaborative learning: Blogging in the foreign language classroom. International Journal of Education and Development using Information and Communication Technology, 4, 21-30.

Dwiyanti, K., Pratama, P., \& Manik, N. (2020). Online learning readiness of junior high school students in Denpasar. Indonesian Journal of English Education, 7(2), 178-188. https://doi.org/10.15408/ijee. v7i2.17773

Elfil, M., \& Negida, A. (2017). Sampling methods in clinical research; an educational review. Emergency, 5(1), e52. https://doi.org/10.22037/emergency.v5i1.15215

Eroglu, M., \& Ozbek, R. (2018). The investigation of the relationship between attitudes towards e-learning and self-directed learning with technology of secondary school students. International Online Journal of Educational Sciences, 10(5), 297-314. https://doi.org/10.15345/iojes.2018.05.019

Findlater, G., Kristmundsdottir, F., Parson, S., \& Gillingwater, T. (2012). Development of a supported self-directed learning approach for anatomy education. Anatomical Sciences Education, 5, 114-121.

Garris, W., Lester, L., Doran, E., Lowery, A., \& Weber, A. (2018). iCollaborate or not: Does technology impede collaborative learning among primary grade students? International Journal of Learning, Teaching and Educational Research, 17(5), 64-81. https://doi.org/10.26803/ijlter.17.5.5

Garrison, D. (1997). Self-directed learning: Toward a comprehensive model. Adult Education Quaterly, $48(1), 18-33$

Gibbons, M. (2002). Self-directed learning handbook. John Wiley \& Sons, Inc.

Gokcearslan, S. (2017). Perspectives of students on acceptance of tablets and self-directed learning with technology. Contemporary Educational Technology, 8(1), 40-55.

Gokhale, A. (1995). Collaborative learning enhances critical thinking. Journal of Technology Education, 7(1), 22-30. https://doi.org/10.21061/jte.v7i1.a.2

Harris, P., Taylor, R., Thielke, R., Payne, J., Gonzalez, N., \& Conde, J. (2009). Research electronic data capture (REDCap)-a metadata-driven methodology and workflow process for providing translational research informatics support. Journal of Biomedical Informatics, 42(2), 377-381.

Henry, M. (2015). Learning in the digital age: Developing critical, creative and collaborative skills. In S. Younie, M. Leask, \& K. Burden (Eds.), Teaching and learning with ICT in the primary school (2nd ed., pp. 1-12). Routledge. 
Hsu, Y., \& Shiue, Y. (2005). The effect of self-directed learning readiness on achievement comparing face-to-face and two-way distance learning instruction. International Journal of Instructional Media, 32(2), 143-156.

Hussain, S., Anwar, S., \& Majoka, M. (2011). Effect of peer group activity-based learning on students' academic achievement in physics at secondary level. International Journal of Academic Research, 3(1), 940-944.

Jonassen, D., Howland, J., Marra, R., \& Crismond, D. (2008). Meaningful learnign with technology (3rd ed.). Pearson Merrill Prentice Hall.

Khalifeh, G., Noroozi, O., Farrokhnia, M., \& Talaee, E. (2020). Higher education students' perceived readiness for computer-supported collaborative learning. Multimodal Technology Interactions, 4(11), 1-13. https://doi.org/10.3390/mti4020011

Khlaif, Z. (2017). Factors influencing teachers' attitudes toward mobile technology integreation in K-12. Technology, Knowledge and Learning, 1-16. https://doi.org/10.1007/s10758-017-9311-6

Labonté, C., \& Smith, V. (2019). Validation of a questionnaire assessing students' self-directed and collaborative learning with and without technology in Canadian middle school classrooms. Canadian Jounral of Learning and Technology, 45(2), 1-19.

Lee, K., Tsai, P.-S., Chai, C., \& Koh, J. (2014). Students' perceptions of self-directed learning and collaborative learning with and without technology. Journal of Computer Assited Learning, 30, 425-437. https://doi.org/10.1111/jcal.12055

Lee, C., Yeung, A., \& Ip, T. (2017). University english language learners' readiness to use computer technology for self-directed learning. System, 67, 99-110. https://doi.org/10.1016/j.system.2017.05.001

Little, R. J. A. (1988). A test of missing completely at random for multivariate data with missing values. Journal of the American Statistical Association, 83(404), 1198-1202. https://doi.org/10.1080/01621 459.1988.10478722

Morris, T., \& Rohs, M. (2021). The potential for digital technology to support self-directed learning in formal education of children: A scoping review. Interactive Learning Environments, 1-14. https:// doi.org/10.1080/10494820.2020.1870501

O’Donnell, A. (2006). Introduction: Learning with technology. In A. O’Donnell, C. Hmelo-Silver, \& G. Erkens (Eds.), Collaborative learning, reasoning, and technology (pp. 1-13). Lawrence Erlbaum Associates.

Partnership for 21st Century Skills. (2011). Framework for 21 st century learning. Washington. Retrieved from http://www.nea.org/home/34888.htm

Pianta, R. C., Hamre, B. K., \& Mintz, S. (2012). Classroom assessment scoring system: 198Secondary manual. Teachstone.

Pich, A., \& Kim, B. (2004). Principles of ICT in education and implementation strategies in Singapore, the province of Alberta in Canada, the United Kingdom, and the Republic of Korea. Journal of Educational Technology Systems, 32(4), 315-335.

Prensky, M. (2001). Digital natives, digital immigrants part 1. On the Horizon, 9(5), 1-6. https://doi.org/ $10.1108 / 10748120110424816$

Quaddumi, H., Bartram, B., \& Qashmar, A. (2021). Evaluating the impact of ICT on teaching and learning: A study of Palestinian students' and teachers' perceptions. Education and Information Technologies, 26(2), 1865-1876.

Qureshi, M., Khaskheli, A., Qureshi, J., Raza, S., \& Yousufi, S. (2021). Factors affecting students' learning performance through collaborative learning and engagement. Interactive Learning Environments, 1-21. https://doi.org/10.1080/10494820.2021.1884886

Resta, P., \& Laferriere, T. (2007). Technology in support of collaborative learning. Educational Psychology Review, 19, 65-83. https://doi.org/10.1007/s10648-007-9042-7

Robertson, J. (2011). The educational affordances of blogs for self-directed learning. Computers \& Education, 57, 1628-1644. https://doi.org/10.1016/j.compedu.2011.03.003

Schwartz, D., Tsang, J., \& Blair, K. (2016). The ABCs of how we learn. W.W. Norton \& Company, Inc.

Semerci, A., \& Aydin, M. (2018). Examining high school teachers' attitudes towards ICT use in education. International Journal of Progressive Education, 14(2), 93-105. https://doi.org/10.29329/ijpe. 2018.139.7

Shamir-Inbal, T., \& Blau, I. (2021). Characteristics of pedagogical change in integrating digital collaborative learning and their sustainability in a school culture: E-CSAMR framework. Journal of Computer Assisted Learning, 37, 825-838. https://doi.org/10.1111/jcal.12526

Simons, P. R. J. (2000). Towards a constructivist theory of self-directed learning. Self-learning, $1-12$. 
Smith, V., Hayes, S., Labonte, C., \& Vargas, F. (2016). Flexible pathways to success: Technology to design for diversity. Alberta Education.

Springer, L., Stanne, M., \& Donovan, S. (1999). Effects of small-group learning on undergraduates in science, mathematics, engineering, and technology: A meta-analysis. Review of Educational Research, 69(1), 21-51.

Statistics Canada. (2011). Population and dwelling count highlight tables, 2011 census. Retrieved January 4, 2022 from https://www12.statcan.gc.ca/census-recensement/2011/dp-pd/hlt-fst/pd-pl/TableTableau.cfm? $\mathrm{LANG}=$ Eng $\& \mathrm{~T}=802 \& \mathrm{PR}=48 \& \mathrm{~S}=51 \& \mathrm{O}=\mathrm{A} \& \mathrm{RPP}=25$

Stewart, R. (2007). Evaluating the self-directed learning readiness of engineering undergraduates: A necessary precursor to project-based learning. World Transactions on Engineering and Technology Education, 6(1), 59-62.

Sze-yeng, F., \& Hussain, R. (2010). Self-directed learning in a socioconstructivist learning environment. Procedia - Social and Behavioral Sciences, 9, 1913-1917. https://doi.org/10.1016/j.sbspro.2010.12. 423

Tabachnick, B., \& Fidell, L. (2014). Cleaning up your act: Screening data prior to analysis. In Tabachnick, B., \& Fidell, L. (Eds.), Using multivariate statistics (pp. 56-110). Allyn \& Bacon.

Tanrikulu, F. (2020). Students' perceptions about the effects of collaborative digital storytelling on writing skills. Computer Assisted Language Learning, 1-16. https://doi.org/10.1080/09588221.2020. 1774611

Terenzini, P., Cabrera, A., Colbeck, C., Parente, J., \& Bjorklund, S. (2001). Collaborative learning vs. lecture/discussion: students' reported learning gains. Journal of Engineering Education, 123-130.

Voogt, J., \& Roblin, N. P. (2012). A comparative analysis of international frameworks for 21st century competences: Implications for national curriculum policies. Journal of Curriculum Studies, 44(3), 299-321. https://doi.org/10.1080/00220272.2012.668938

Wen, Y., Gwendoline, C., \& Lau, S. (2021). ICT-supported home-based learning in K-12: A systematic review of research and implementation. TechTrends, 65, 371-378. https://doi.org/10.1007/ s11528-020-00570-9

Willett, J., Yamashita, J., \& Anderson, R. (1983). A meta-analysis of instructional systems applied in science teaching. Journal of Research in Science Teaching, 20(5), 405-417.

Xie, K., Nelson, M., Cheng, S.-L., \& Jiang, Z. (2021). Examining changes in teachers' perceptions of extern. Journal of Research on Technology in Education, 1-26. https://doi.org/10.1080/15391523. 2021.1951404

Publisher's note Springer Nature remains neutral with regard to jurisdictional claims in published maps and institutional affiliations. 